\title{
Effects of rolipram on U46619-induced contraction and cyclic nucleotide content in the porcine coronary artery
}

\author{
Takeharu KAnEDA ${ }^{1}$, Takashi KuBota ${ }^{1}$, Kenji FujIMOTO ${ }^{1}$, \\ Norimoto URAKAWA ${ }^{1}$, Shinjiro NAKAJYO ${ }^{1}$ and Kazumasa SHIMIZU ${ }^{1}$ \\ ${ }^{1}$ Laboratory of Veterinary Pharmacology, Department of Veterinary Medicine, \\ Veterinary and Life Science University, Japan
}

Received September 24, 2009; Accepted November 25, 2009

\begin{abstract}
The effects of various selective phosphodiesterase (PDE) inhibitors on muscle contractility and cyclic nucleotide content in the porcine coronary artery were investigated. Various selective PDE inhibitors, vinpocetine (type 1), erythro-9-(2hydroxy-3-nonyl) adenine (EHNA, type 2), milrinone (type 3), rolipram (type 4), Ro201724 (type 4), and zaprinast (type 5), inhibited U46619-induced contractions in a concentration-dependent manner. The rank order of potency for the porcine coronary artery was rolipram $>$ Ro20-1724 $>$ milrinone $>$ vinpocetine $>$ zaprinast $>$ EHNA, which was different from that of both the porcine carotid artery and aorta. Rolipram inhibited the U46619-induced muscle tension with a decreased $\left[\mathrm{Ca}^{2+}\right]_{\mathrm{i}}$ level, but inhibited the high $\mathrm{K}^{+}$induced contraction without a change in $\left[\mathrm{Ca}^{2+}\right]_{\mathrm{i}}$ level. Rolipram increased cAMP but not cGMP content. Iberiotoxin restored the inhibition of muscle tension and the $\left[\mathrm{Ca}^{2+}\right]_{i}$ levels induced by rolipram. U46619 and caffeine induced a transient increase in the $\left[\mathrm{Ca}^{2+}\right]_{\mathrm{i}}$ levels in a $\mathrm{Ca}^{2+}$-free solution, but rolipram only inhibited the U46619-induced $\mathrm{Ca}^{2+}$ transient. In conclusion, rolipram is the most potent inhibitor in the porcine coronary artery, but not in the carotid artery and aorta. Moreover it is suggested that the mechanism by which rolipram causes relaxation is due to a decrease in the $\left[\mathrm{Ca}^{2+}\right]_{\mathrm{i}}$ levels and of the $\mathrm{Ca}^{2+}$ sensitivity of the contractile elements to cAMP.
\end{abstract}

Key words: rolipram, coronary artery, cAMP, phosphodiesterase, intracellular $\mathrm{Ca}^{2+}$

\section{Introduction}

Cyclic adenosine monophosphate (cAMP) and cyclic guanosine monophosphate (cGMP) are important second messengers, and are associated with smooth muscle relaxation (Diamond, 1978). These cyclic nucleotides are synthesized by adenylyl cyclase or guanylyl cyclase, and are degraded by phosphodiesterases (PDEs). Currently, PDEs are classified into 11 families (Beavo, 1955; Fawcett et al., 2000; Yuasa et al., 2000), and selective PDE inhibitors have been

Correspondence to: Dr. Takeharu Kaneda, Laboratory of Veterinary Pharmacology, Department of

Veterinary Medicine, Veterinary and Life Science University, 7-1 Kyonan-cho 1-chome, Musashino, Tokyo

180-8602, Japan

Phone: +81-422-31-4457 Fax: +81-422-31-4457 e-mail: t-kaneda@nvlu.ac.jp 
found (Beavo and Reifsnyder, 1990). In the case of the cardiovascular system, PDE3 is one of the major PDE isozymes. Actually, selective PDE3 inhibitors such as milrinone and enoximone are used in the management of acute heart failure. It has been shown that the treatment effects of these PDE3 inhibitors are their positive inotropic action and the vasodilation due to increases in cAMP (Kikura and Levy, 1995; Shipley et al., 1996).

Vascular smooth muscle cells (VSMCs) can exist as 2 distinct phenotypes, contractile and synthetic (Yoshida and Owens, 2005; Owens et al., 2004). In healthy blood vessels, contractile VSMCs contract and dilate in response to numerous hormonal or biophysical demands. In vascular abnormalities such as atherosclerosis, growth factors and cytokines induce a phenotypic change in VSMCs from the contractile state to the synthetic state. Recently, it has been shown that PDE4 activity surpassed PDE3 activity in synthetic VSMCs (Houslay et al., 2007). However, there are few papers that shown the effects of PDE4 inhibitors on muscle contraction in normal vascular vessels (Lindgren et al., 1991; Noguera et al., 2001).

In the present study, we have demonstrated the effects of selective PDE (type 1-5) inhibitors on contractility of the porcine coronary artery, and compared that with those of both the porcine carotid artery and aorta. In addition, we also investigated the relaxing mechanisms of rolipram in the coronary artery.

\section{Materials and Methods}

\section{Muscle preparations and tension measurement}

The heart, carotid arteries and thoracic aorta were removed from adult pigs of either sex at the local abattoir. In each case, the medial layer of the left coronary artery was isolated from the hearts and cut into spiral strips. The carotid artery and thoracic aorta were prepared by removing the adventitia and cutting rings into circular strips. All strips were 2- to 3-mm wide and 8 - to $10-\mathrm{mm}$ long. The endothelium was removed by gentle rubbing of the inner surface of the strips with absorbent cotton. The muscle strips were incubated with physiological salt solution (PSS) containing (in $\mathrm{mM}$ ) $136.8 \mathrm{NaCl}, 5.4 \mathrm{KCl}, 1.5 \mathrm{CaCl}_{2}, 1.0 \mathrm{MgCl}_{2}, 11.9 \mathrm{NaHCO}_{3}$, and 5.6 glucose. PSS was aerated with $95 \% \mathrm{O}_{2}$ and $5 \% \mathrm{CO}_{2}$ to adjust $\mathrm{pH}$ to 7.2 at $37^{\circ} \mathrm{C}$. Muscle tension was recorded isometrically. One end of each strip was tied to a glass holder and the other end was connected by a silk thread to a strain-gauge transducer (TB-611T; Nihon Kohden, Tokyo) in an organ bath containing PSS with a resting tension of $1 \mathrm{~g}$ for both the coronary and carotid artery, and $10 \mathrm{~g}$ for the thoracic aorta. The muscle strips were equilibrated for $30 \mathrm{~min}$ to obtain a stable contractility induced by isosmotically added $40 \mathrm{mM} \mathrm{KCl}$. When the contractile response induced by $1 \mu \mathrm{M}$ U46619 reached a steady level about 15-20 min after addition to the preparations, either vinpocetine (type 1), EHNA (type 2), milrinone (type 3), rolipram (type 4), Ro20-1724 (type 4) or zaprinast (type 5) were added cumulatively.

\section{Simultaneous measurement of a muscle contraction and $\left[\mathrm{Ca}^{2+}\right]_{i}$ level}

The $\left[\mathrm{Ca}^{2+}\right]_{\mathrm{i}}$ level was measured simultaneously with each muscle contraction as reported previously (Ozaki et al., 1987). Muscle strips were incubated overnight at $4^{\circ} \mathrm{C}$ with PSS containing $5 \mu \mathrm{M}$ fura $2 / \mathrm{AM}$ and $0.02 \%$ cremophor EL (a non-cytotoxic detergent) to increase the solubility of 
fura2/AM. One end of the muscle was pinned to the bottom of the organ bath which was filled with $8 \mathrm{ml}$ of PSS, and the other end attached to the transducer with silk thread. The muscle strip was held horizontally in the organ bath. The muscle strip was alternately excited with light at either $340 \mathrm{~nm}$ or $380 \mathrm{~nm}$ using a rotating filter wheel, while the $500 \mathrm{~nm}$ emission was measured through a band-pass filter with a fluorometer (CAF-100; Japan Spectroscopic Co., Ltd., Tokyo). The fluorescence emission ratio (F340/F380) was recorded as an indicator of $\left[\mathrm{Ca}^{2+}\right]_{\mathrm{i}}$. The fluorescence ratio was expressed as a percentage, by assigning the values at rest in normal PSS to be $0 \%$ and those at a steady level of $\left[\mathrm{Ca}^{2+}\right]_{\mathrm{i}}$ in $1 \mu \mathrm{M}$ U46619 or $40 \mathrm{mM} \mathrm{Kcl}$ to be $100 \%$.

\section{Assay of cGMP or cAMP content}

The cGMP and cAMP content of the muscle strips was measured by enzyme immunoassay, as reported previously (Kaneda et al., 2004). After incubation of the strips with each of the PDE inhibitors for $10 \mathrm{~min}$ in the presence of $\mathrm{U} 46619(1 \mu \mathrm{M})$, the strips were rapidly frozen in liquid nitrogen, and stored at $-80^{\circ} \mathrm{C}$ until homogenized in $6 \%$ trichloroacetic acid $(0.4 \mathrm{ml})$. The homogenate was centrifuged at 3,000 $\times \mathrm{g}$ for $15 \mathrm{~min}$, and the supernatant washed four times with $1.5 \mathrm{ml}$ of water-saturated diethyl ether. The cGMP and cAMP content of the strips was assayed with an enzyme immunoassay kit (GE Healthcare, UK). The cGMP and cAMP content was expressed as picomoles per gram wet weight of tissue.

\section{Chemicals}

The chemicals used were milrinone, zaprinast (Sigma-Aldrich, St. Louis, MO, USA), vinpocetine, erythro-9-(2-hydroxy-3-nonyl) adenine $\cdot \mathrm{HCl}$ (EHNA), rolipram, U46619 (BIOMOL Research Laboratories, USA) and Ro20-1724 (LC Laboratories, New Boston, USA). The concentration of vinpocetine was held below $30 \mu \mathrm{M}$ in the present experiments as it will crystallize if its concentration exceeds $30 \mu \mathrm{M}$ in PSS.

\section{Statistics}

Values are expressed as the mean $\pm \mathrm{SEM}$, and the $\mathrm{IC}_{50}$ values (the concentration producing $50 \%$ relaxation) were determined by linear regression analysis. Statistical analyses were performed by using the Student's $t$-test, and probabilities less than $5 \%$ were considered significant $(P<0.05)$.

\section{Results}

\section{Effects of various PDE inhibitors on high $K^{+}$and U46619-induced contractions}

High $\mathrm{K}^{+}(40 \mathrm{mM})$ and $\mathrm{U} 46619$ induced sustained contractions in the coronary artery. Vinpocetine (type 1), EHNA (type 2), milrinone (type 3), rolipram (type 4), Ro20-1724 (type 4) and zaprinast (type 5) inhibited these high $\mathrm{K}^{+}$and $\mathrm{U} 46619$-induced contractions in a concentration-dependent manner in the coronary artery (Fig. 1). The concentrations of these agents producing $50 \%$ relaxation $\left(\mathrm{IC}_{50}\right)$ of both the high $\mathrm{K}^{+}$- and $\mathrm{U} 46619$-induced contractions is presented in Table 1. In the present experiment, these PDE inhibitors inhibited U46619induced contractions more potently than those of high $\mathrm{K}^{+}$- induced contractions. The rank order 

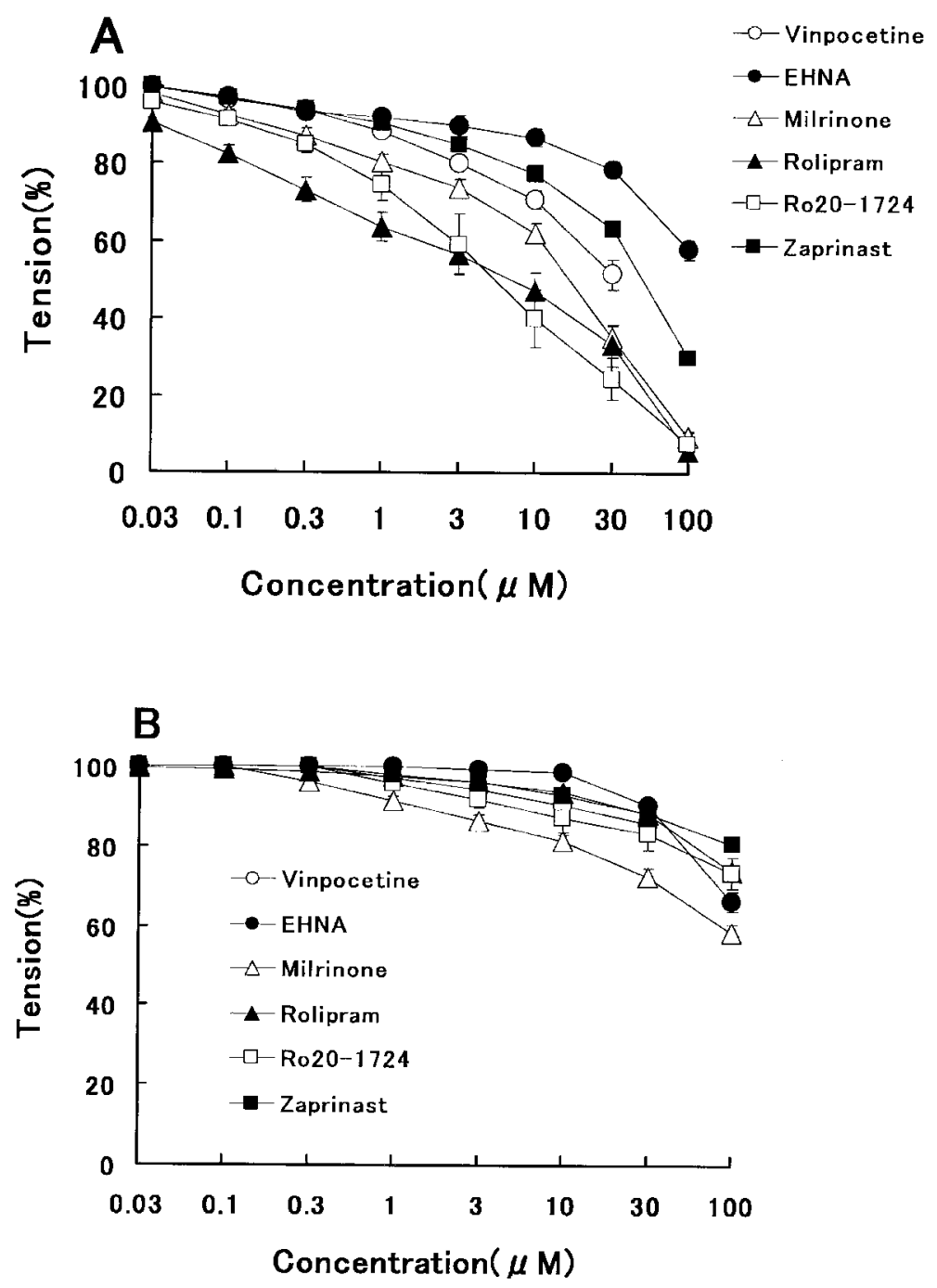

Fig. 1. The effects of vinpocetine $(\bigcirc)$, EHNA ( $)$, milrinone $(\triangle)$, Ro20-1724 ( $\mathbf{\Delta}$ ), rolipram $(\square)$ and zaprinast $(\square)$ on contractions induced by $1 \mu \mathrm{M}$ U46619 (A) and $40 \mathrm{mM} \mathrm{KCl}$ (B) in preparations of the porcine coronary artery. The contractions induced by $1 \mu \mathrm{M}$ $\mathrm{U} 46619$ or $40 \mathrm{mM} \mathrm{KCl}$ just before the application of these PDE inhibitors were taken as $100 \%$. Each point represents the mean of 4-7 preparations. Vertical bars indicate the SEM.

for the relaxant effect was rolipram $>$ Ro20-1724 $>$ milrinone $>$ vinpocetine $>$ zaprinast $>$ EHNA for the U46619-induced contractions.

Effects of various PDE inhibitors on cGMP and cAMP content

Milrinone $(100 \mu \mathrm{M})$, rolipram $(100 \mu \mathrm{M})$ and Ro20-1724 $(100 \mu \mathrm{M})$ caused a significant increase in the cAMP content (Fig. 2A). On the other hand, zaprinast (100 $\mu \mathrm{M})$ only caused a significant increase in the cGMP content (Fig. 2B). 
Table 1. $\mathrm{IC}_{50}$ of various selective PDE inhibitors

\begin{tabular}{lcc}
\multicolumn{3}{c}{ in coronary artery } \\
\hline \multicolumn{2}{c}{ Agents } & $\mathrm{IC}_{50}(\mu \mathrm{M})$ \\
& $40 \mathrm{~K}^{+}$ & $\mathrm{U} 46619(1 \mu \mathrm{M})$ \\
\hline Vinpocetine & $>100$ & $20(16.8-24.9)$ \\
EHNA & $>100$ & $>100$ \\
Milrinone & $>100$ & $7.9(6.6-9.3)$ \\
Ro20-1724 & $>100$ & $4.0(2.8-5.9)$ \\
Rolipram & $>100$ & $3.4(2.4-4.9)$ \\
Zaprinast & $>100$ & $40(39.5-47.0)$ \\
\hline
\end{tabular}

Numbers in parentheses indicate $95 \%$ confidence limits. $n=4-7$.
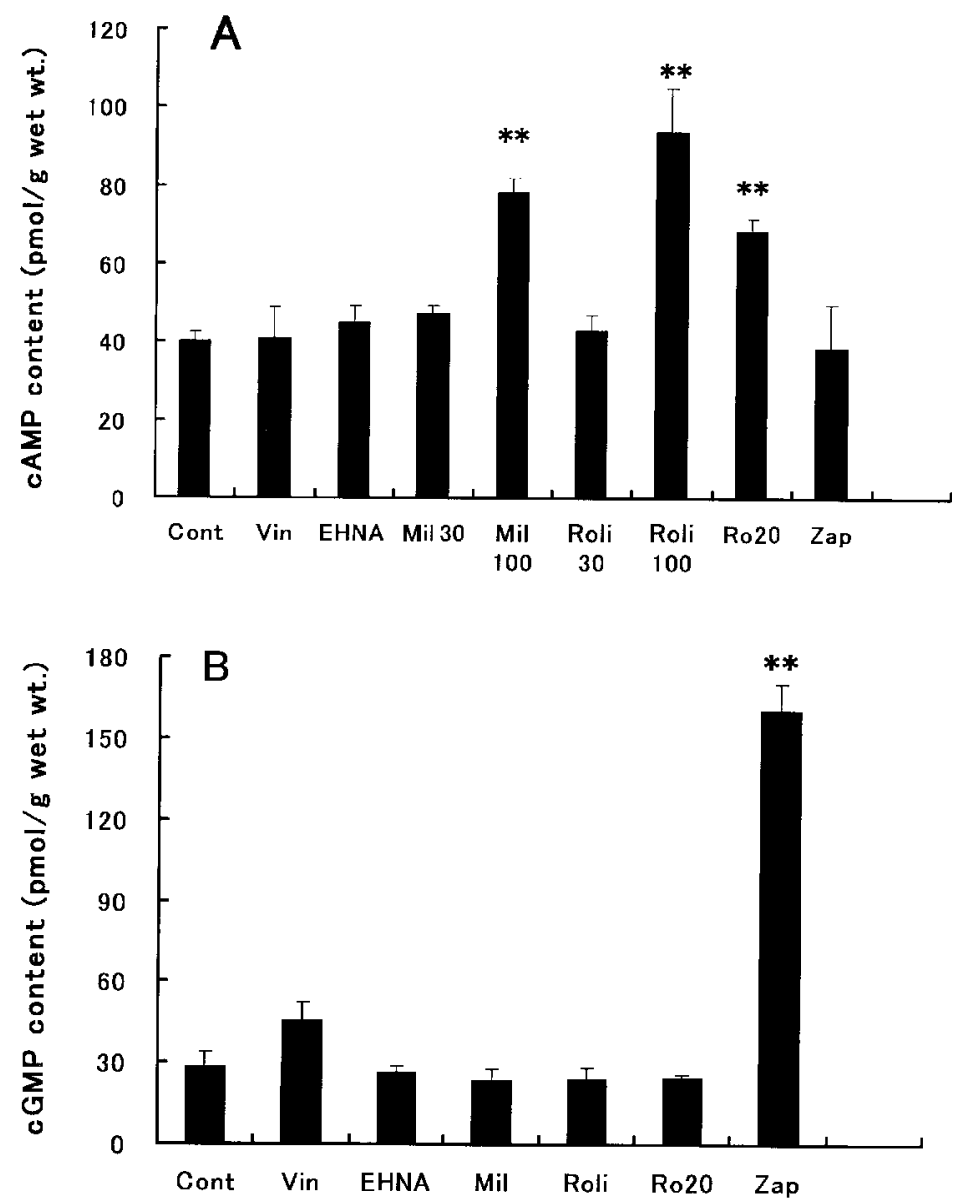

Fig. 2. The effects of vinpocetine (30 $\mu \mathrm{M}$, Vin), EHNA $(100 \mu \mathrm{M})$, milrinone $(30 \mu \mathrm{M}$, Mil 30 , $100 \mu \mathrm{M}$, Mil 100), rolipram (30 $\mu \mathrm{M}$, Roli 30; $100 \mu \mathrm{M}$, Roli 100), Ro20-1724 (100 $\mu \mathrm{M}$, Ro 20) and zaprinast (Zap) on the cAMP (A) and cGMP (B) contents of the porcine coronary artery. Preparations were precontracted with $1 \mu \mathrm{M}$ U46619, and were treated with these agents for $10 \mathrm{~min}$. The control was treated with vehicle instead of these PDE inhibitors. Each point represents the mean of 4 experiments. Vertical bars indicate the SEM. **, significant difference from control. 
A
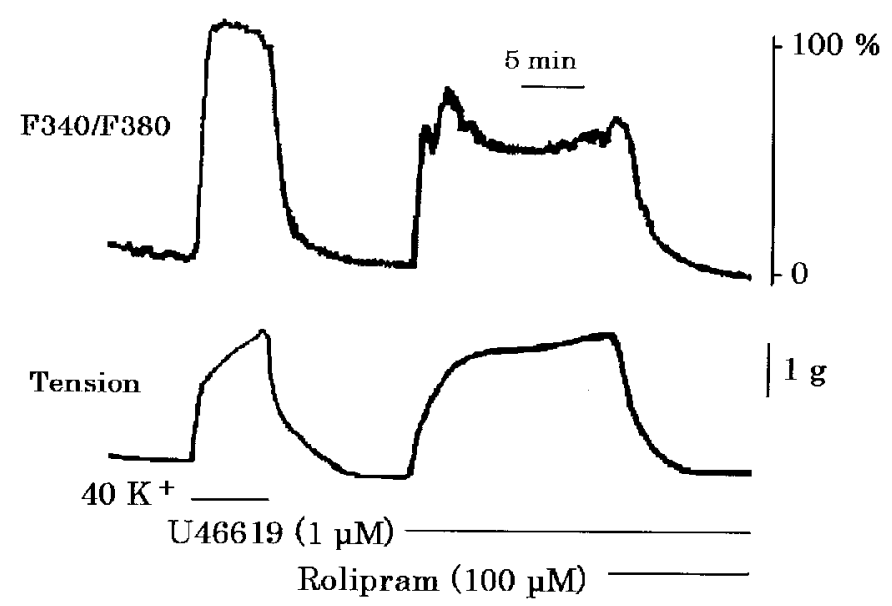

B

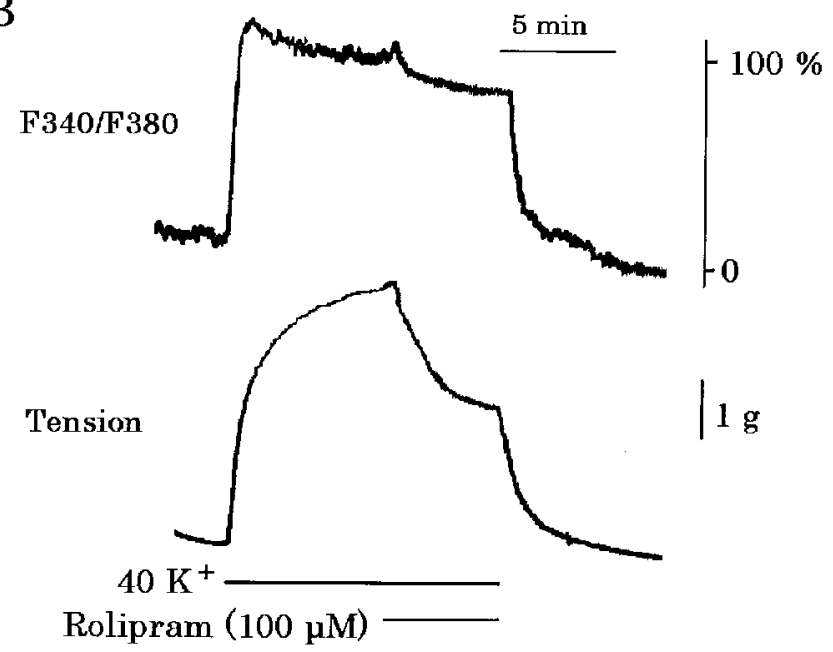

Fig. 3. Effects of rolipram on the U46619-induced (A) or $40 \mathrm{mM} \mathrm{KCl-induced}\left(40 \mathrm{~K}^{+}, \mathrm{B}\right)$ increase in $\left[\mathrm{Ca}^{2+}\right]_{\mathrm{i}}$ levels (F340/F380, upper trace) and muscle tension (lower trace). The increase in $\left[\mathrm{Ca}^{2+}\right]_{\mathrm{i}}$ levels induced by $\mathrm{U} 46619$ or $40 \mathrm{mM} \mathrm{K} \mathrm{K}^{+}$just before an application of rolipram was taken as $100 \%$. Each trace was obtained from typical results of $4-5$ experiments.

Effects of rolipram on high $\mathrm{K}^{+}$and U46619-induced increases in both $\left[\mathrm{Ca}^{2+}\right]_{i}$ levels and muscle tension

The effects of rolipram on $\left[\mathrm{Ca}^{2+}\right]_{\mathrm{i}}$ levels were measured simultaneously with changes in muscle tension, using a fluorescent $\mathrm{Ca}^{2+}$ indicator, fura2. Either $40 \mathrm{mM} \mathrm{K}{ }^{+}$or U46619 induced muscle contraction and elevated $\left[\mathrm{Ca}^{2+}\right]_{\mathrm{i}}$ levels as indicated by the ratio of F340/F380. Rolipram (30 or $100 \mu \mathrm{M}$ ) decreased both muscle tension and the increases of $\left[\mathrm{Ca}^{2+}\right]_{\mathrm{i}}$ levels induced by $\mathrm{U} 466189\left(35.1 \pm 2.2 \%\right.$ for tension and $26.5 \pm 1.7 \%$ for $\left[\mathrm{Ca}^{2+}\right]_{\mathrm{i}}$ level at $30 \mu \mathrm{M}, \mathrm{n}=4$, data not shown; $2.8 \pm 2.8 \%$ for tension and $1.7 \pm 1.7 \%$ for $\left[\mathrm{Ca}^{2+}\right]_{\mathrm{i}}$ level at $100 \mu \mathrm{M}, \mathrm{n}=5$, Fig. 3A). The resting 
tension and $\left[\mathrm{Ca}^{2+}\right]_{\mathrm{i}}$ levels were not affected by the BK channel blocker iberiotoxin (30 nM; IbTX). In the presence of IbTX (30 nM), inhibition of the U466189 (30 $\mu \mathrm{M})$-induced muscle tension and the increase in $\left[\mathrm{Ca}^{2+}\right]_{\mathrm{i}}$ levels caused by rolipram $(30 \mu \mathrm{M})$ were partially reversed (from $35.1 \pm 2.2 \%$ to $58.7 \pm 3.5 \%$ for tension, $\mathrm{n}=4, P<0.01$, from $26.5 \pm 1.7 \%$ to $46.3 \pm 4.2 \%$ for $\left[\mathrm{Ca}^{2+}\right]_{\mathrm{i}}$ level, $\mathrm{n}=4, P<0.01$, data not shown).

Rolipram also decreased both muscle contraction and the increases in $\left[\mathrm{Ca}^{2+}\right]_{\mathrm{i}}$ levels induced by $40 \mathrm{mM} \mathrm{K}$, but the decrease in $\left[\mathrm{Ca}^{2+}\right]_{\mathrm{i}}$ levels was not significant $(81.3 \pm 6.0 \%, \mathrm{n}=4$; Fig. $3 \mathrm{~B})$.

Effects of rolipram on U466189 or caffeine induced increase in $\left[\mathrm{Ca}^{2+}\right]_{i}$ levels and contraction in the absence of extracellular $\mathrm{Ca}^{2+}$

In $\mathrm{Ca}^{2+}$-free solution (using $2 \mathrm{mM}$ EGTA), U46619 $(1 \mu \mathrm{M})$ induced a sustained increase in muscle tension and a transient increase in $\left[\mathrm{Ca}^{2+}\right]_{\mathrm{i}}$ levels $(71.5 \pm 4.1 \%$ for tension, $40.0 \pm 3.3 \%$ for $\left[\mathrm{Ca}^{2+}\right]_{\mathrm{i}}$ levels of the high $\mathrm{K}^{+}$-induced response, $\left.\mathrm{n}=6\right)$. Rolipram $(100 \mu \mathrm{M})$ diminished the transient increase in both muscle tension and $\left[\mathrm{Ca}^{2+}\right]_{\mathrm{i}}$ levels elicited by $\mathrm{U} 46619$ to $37.6 \pm 7.5 \%$ and $21.8 \pm 1.2 \%$ (Fig. 4 ).

Caffeine $(20 \mathrm{mM})$ also induced a transient increase in muscle tension and $\left[\mathrm{Ca}^{2+}\right]_{\mathrm{i}}$ levels in $\mathrm{Ca}^{2+}$-free solution $\left(14.1 \pm 1.0 \%\right.$ for tension, $100.6 \pm 2.0 \%$ for $\left[\mathrm{Ca}^{2+}\right]_{\mathrm{i}}$ level of high $\mathrm{K}^{+}$-induced response, $\mathrm{n}=5)$. Rolipram $(100 \mu \mathrm{M})$ had no significant effect on the caffeine-induced transient increase in both muscle tension and $\left[\mathrm{Ca}^{2+}\right]_{\mathrm{i}}$ levels $\left(19.4 \pm 1.8 \%\right.$ for tension, $102.1 \pm 4.3 \%$ for $\left[\mathrm{Ca}^{2+}\right]_{\mathrm{i}}$ level, data not shown).

Effects of various selective PDE inhibitors on contractility in carotid artery and thoracic aorta preparations

Vinpocetine, EHNA, milrinone, rolipram, Ro20-1724, and zaprinast inhibited U46619-induced contractions in a concentration-dependent manner in both porcine carotid artery and thoracic aorta preparations (Fig. 5). The concentrations of $\mathrm{IC}_{50}$ are presented in Table 2 . In both carotid artery and thoracic aorta preparations, milrinone only inhibited U46619-induced contractions to resting levels at their maximum concentration.

The rank orders for the relaxant effects were milrinone > vinpocetine, EHNA, Ro20-1724, rolipram, zaprinast for the carotid artery, and milrinone $>$ zaprinast $>$ vinpocetine, EHNA, Ro 201724 , rolipram for the thoracic aorta.

\section{Discussion}

In the present study, the effects of the selective PDE (type 1-5) inhibitors on the contractility of preparations of the porcine coronary artery were compared with those of both the porcine carotid artery and aorta. Moreover, we also investigated the relaxing mechanism of rolipram in the porcine coronary artery. The major findings are as follows: (1) The rank order for the relaxant effect were rolipram $>$ Ro20-1724 $>$ milrinone $>$ vinpocetine $>$ zaprinast $>$ EHNA for U46619-induced contraction. (2) In the presence of U46619, $100 \mu \mathrm{M}$ rolipram increased the content of cAMP significantly, but not that of cGMP. (3) As has been reported for many cyclic nucleotide-related agents, rolipram also inhibited U46619-induced muscle tension with a 

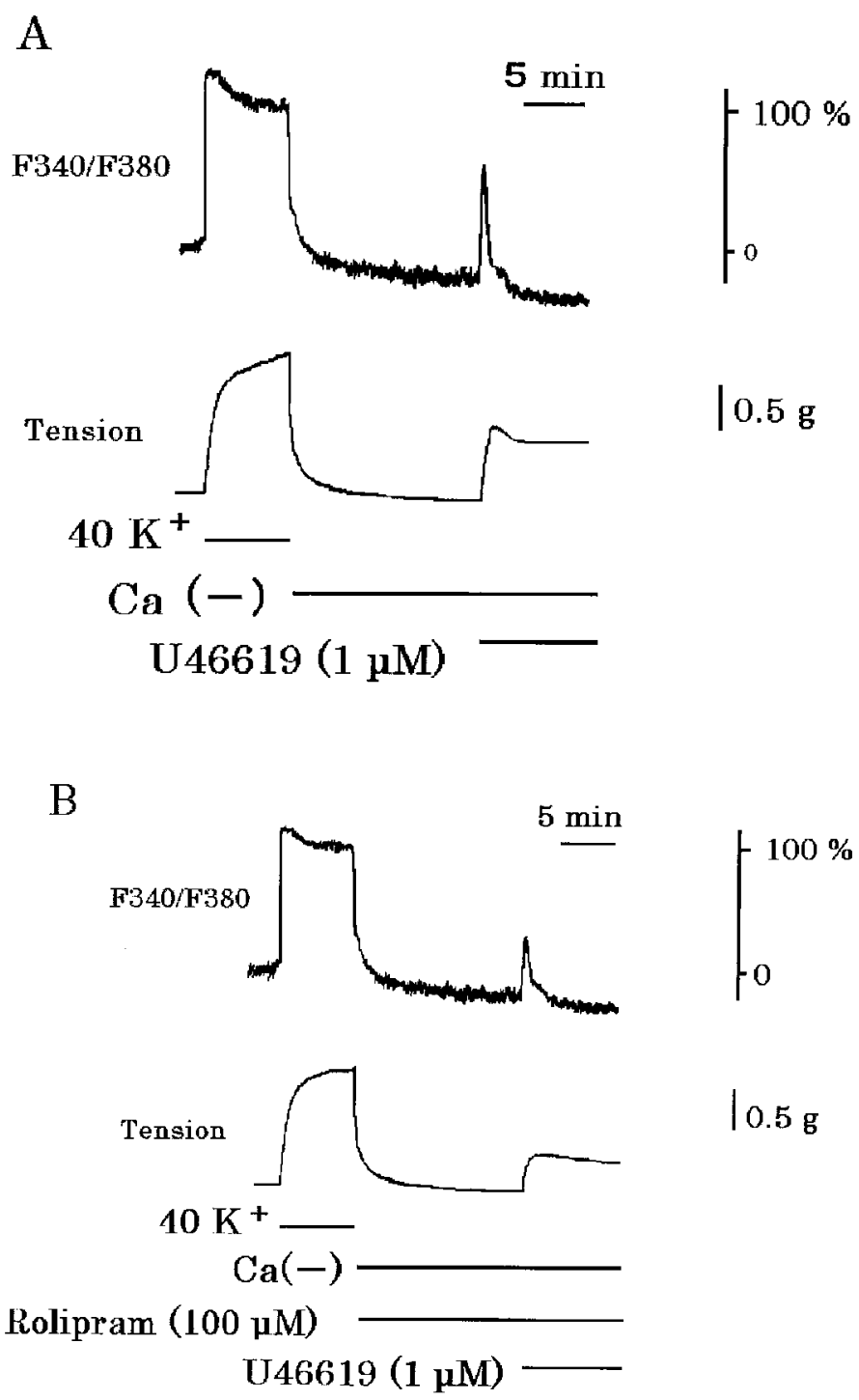

Fig. 4. Representative recordings showing the increase in $\left[\mathrm{Ca}^{2+}\right]_{\mathrm{i}}$ levels $(\mathrm{F} 340 / \mathrm{F} 380$, upper trace) and muscle tension (lower trace) induced by U46619 in $\mathrm{Ca}^{2+}$-free PSS containing $2 \mathrm{mM}$ EGTA, in the absence (A) and presence (B) of rolipram. Rolipram was applied $15 \mathrm{~min}$ prior to the application of U46619. The increase in $\left[\mathrm{Ca}^{2+}\right]_{\mathrm{i}}$ levels induced by $40 \mathrm{mM} \mathrm{K}^{+}$at $5 \mathrm{~min}$ in normal PSS was taken as $100 \%$. Each trace, typical results from $4-5$ experiments.

decrease in $\left[\mathrm{Ca}^{2+}\right]_{\mathrm{i}}$ levels. (4) In preparations of both the porcine carotid artery and aorta, the inhibitory effects of both rolipram and Ro20-1724 on the U46619-induced contraction were lower than those of other PDE inhibitors used in our study.

PDEs are involved in the regulation of signal transductions, and therefore various PDEs play important roles in mediating different cellular functions. Several studies have shown the functional role of PDE families in vascular smooth muscle. In the endothelium-denuded aorta, 

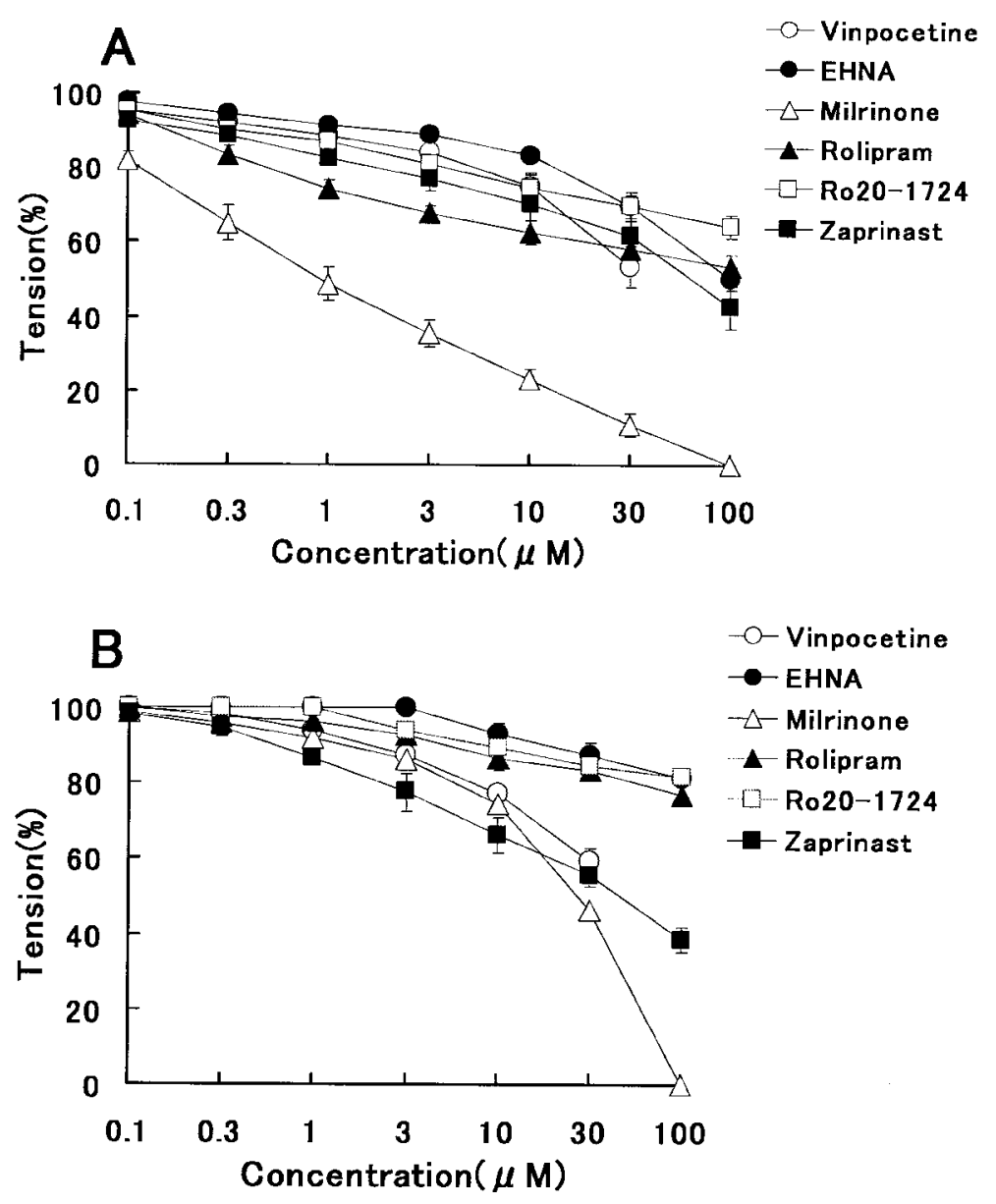

Fig. 5. The effects of vinpocetine $(\bigcirc)$, EHNA ( $)$, milrinone $(\triangle)$, Ro20-1724 ( $\mathbf{\Delta}$ ), rolipram $(\square)$ and zaprinast $(\square)$ on contractions induced by $1 \mu \mathrm{M}$ U46619 in preparations of the porcine carotid artery (A) and aorta (B). The contractions induced by $1 \mu \mathrm{M}$ U46619 just before the application of these PDE inhibitors were taken as $100 \%$. Each point represents the mean of 4-7 preparations. Vertical bars indicate the SEM.

Table 2. $\mathrm{IC}_{50}$ and maximal inhibition (\%) of various selective PDE inhibitors for contraction induced by U46619 in carotid artery and aorta

\begin{tabular}{lcccccc}
\hline & Vinpocetine & EHNA & Milrinone & Ro20-1724 & Rolipram & Zaprinast \\
\hline $\begin{array}{l}\text { Carotid artery } \\
\mathrm{IC}_{50}(\mu \mathrm{M})\end{array}$ & $>30$ & $>100$ & 1.1 & $>100$ & $>100$ & 83.1 \\
& & & $(0.8-1.4)$ & & & $(41.0->100)$ \\
Maximal inhibition (\%) & $46.5 \pm 5.5$ & $49.9 \pm 3.2$ & 100 & $35.8 \pm 3.3$ & $46.7 \pm 3.3$ & $57.5 \pm 5.9$ \\
$\mathrm{n}$ & 6 & 6 & 6 & 5 & 6 & 6 \\
\hline Aorta & $>30$ & $>100$ & 11.1 & $>100$ & $>100$ & 46.3 \\
$\mathrm{IC}$ & & $(10.6-11.6)$ & & $(30.5-70.2)$ \\
Maximal inhibition $(\%)$ & $40.7 \pm 3.1$ & $18.8 \pm 1.7$ & 100 & $18.4 \pm 1.2$ & $23.1 \pm 2.7$ & $61.5 \pm 3.3$ \\
$\mathrm{n}$ & 5 & 5 & 6 & 5 & 6 & 6 \\
\hline
\end{tabular}

Numbers in parentheses indicate $95 \%$ confidence limits. The inhibition induced by PDE inhibitors which fully recover to the basal tension before the application of U46619 $(1 \mu \mathrm{M})$ was taken as $100 \%$ inhibition. 
the relaxing effect of PDE3 inhibitors was the most potent of the selective PDE inhibitors (Komas et al., 1991). On the other hand, the inhibitory effect of rolipram (type 4) on phenylephrine-induced contraction was more potent than that of milrinone (type 3 ) in the renal artery (Karsten et al., 2003). In the present study, the selective PDE inhibitors inhibited the U46619-induced contraction and the rank order for the relaxant effect were rolipram > Ro20$1724>$ milrinone $>$ vinpocetine $>$ zaprinast $>$ EHNA in the porcine coronary artery. In contrast, the inhibitory effects of rolipram and Ro20-1724 on the U46619-induced contraction were less potent than those of milrinone and other PDE inhibitors in both the porcine carotid artery and aorta. These results indicate that PDE3 isozymes express in the smooth muscle of both elastic and muscular arteries, and regulate the smooth muscle contraction, however, PDE4 isozymes express only in muscular arteries. Moreover, the expressions of other PDE isozymes may be also different in various arteries.

In the present study, we could not detect an increase in cAMP in the mid-range concentrations of milrinone and rolipram or other PDE inhibitors used in the present study. Other researchers have shown that the PDE inhibitors, such as rolipram or cilostamide, increase the cAMP content at only very high concentrations (Eckly and Lugnier, 1994; Schoeffter et al., 1987). These dissociations between vasodilation and increases in cAMP content have been shown in other cAMP elevating agents such as forskolin, isoproterenol and prostaglandin $\mathrm{E}_{1}$ (Vegesna and Diamond, 1986). However, it has been reported that PDE3 and PDE4 inhibitors potentiate the relaxant effects and/or cAMP elevation produced by isoproterenol or forskolin in vascular smooth muscle (Tanaka et al., 1988; Lindgren et al., 1990; Maurice et al., 1991). It has been proposed that cAMP signaling involves its sequestration into functional sub-cellular compartments and that significant local increases in cAMP in the cell are immeasurable (Vegesna and Diamond, 1986). On the other hand, it has been reported that the vasorelaxant action of amlinone, a PDE3 inhibitor, does not involve a cAMP-dependent pathway (van der Zypp et al., 2000). Changes in the local cyclic nucleotide concentration remain to be clarified.

It has been reported that cAMP-related agents inhibited U46619 muscle tension and increases in $\left[\mathrm{Ca}^{2+}\right]_{\mathrm{i}}$ levels, however, the inhibition of high $\mathrm{K}^{+}$-induced muscle tension with a slight decreases in $\left[\mathrm{Ca}^{2+}\right]_{\mathrm{i}}$ levels in the porcine coronary artery (Yamagishi et al., 1994; Yamanaka et $a l ., 2003)$. In this study, rolipram inhibited the U46619-induced muscle tension with a decrease in $\left[\mathrm{Ca}^{2+}\right]_{\mathrm{i}}$ levels, but inhibited the high $\mathrm{K}^{+}$-induced contraction without changes in $\left[\mathrm{Ca}^{2+}\right]_{\mathrm{i}}$ levels. Thus, this suggests that the decrease in $\left[\mathrm{Ca}^{2+}\right]_{\mathrm{i}}$ levels caused by rolipram is due to a cAMP-dependent pathway.

In the present study, pretreatment with IbTX, a large-conductance $\mathrm{Ca}^{2+}$-activated $\mathrm{K}^{+}$channel (BK channel) blocker, partially reversed the inhibition of the U46619-induced muscle tension and the increases in $\left[\mathrm{Ca}^{2+}\right]_{\mathrm{i}}$ levels by rolipram. In whole cell patch-clamp experiments, IbTX reduced isoproterenol (Iso)-enhanced $\mathrm{K}^{+}$currents in smooth muscle cells isolated from the rat coronary artery ( $\mathrm{Li}$ et al., 2003). Thus, the decrease in $\left[\mathrm{Ca}^{2+}\right]_{\mathrm{i}}$ levels caused by rolipram may involve BK channels in the porcine coronary artery. Other mechanisms for the cAMP-induced decrease in $\left[\mathrm{Ca}^{2+}\right]_{\mathrm{i}}$ levels have been proposed, the stimulation of $\mathrm{Ca}^{2+}$ uptake into intracellular stores (Raeymaekers et al., 1990), including and an increase in $\mathrm{Ca}^{2+}$ extrusion from the cell by 
both the sarcolemmal $\mathrm{Ca}^{2+}$ pump (Bülbring and Tomita, 1987) and $\mathrm{Na}^{+}-\mathrm{Ca}^{2+}$ exchanger (NCX) (Yamanaka et al., 2003). In the porcine coronary artery, U46619 and caffeine induced a transient increase in $\left[\mathrm{Ca}^{2+}\right]_{\mathrm{i}}$ levels in a $\mathrm{Ca}^{2+}$-free solution (Yamagishi, 1994). They also showed that both Iso and IBMX significantly inhibited the U46619-induced $\mathrm{Ca}^{2+}$ transient, but not the caffeineinduced one. That is similar to our present data for rolipram. These results suggest that cAMP may decrease phosphatidylinositol turnover for the inhibition of the U46619-induced $\mathrm{Ca}^{2+}$ transient, but not stimulate $\mathrm{Ca}^{2+}$ uptake into intracellular stores, in the porcine coronary artery. The involvement of the sarcolemmal $\mathrm{Ca}^{2+}$ pump and the NCX in the cAMP-induced decrease in $\left[\mathrm{Ca}^{2+}\right]_{\mathrm{i}}$ levels of smooth muscle has been reported mainly in vascular smooth muscle (Ishida and Paul, 2005). Yamanaka et al. (2003) showed that pretreatment with low $\mathrm{Na}^{+}$physiological salt solution (PSS) partially reversed the inhibition of U46619-induced muscle tension and the increase in $\left[\mathrm{Ca}^{2+}\right]_{\mathrm{i}}$ levels by Iso, and Iso-induced decrease in tension during contraction by U46619 was greatly inhibited by 2',4'-dichlorobenzamil, a forward- and reverse-mode NCX inhibitor. Further study is needed to clarify the regulation of $\left[\mathrm{Ca}^{2+}\right]_{i}$ levels in the smooth muscle of the coronary artery.

In the present study, rolipram reduced both muscle tension and the increase of $\left[\mathrm{Ca}^{2+}\right]_{\mathrm{i}}$ levels induced by high $\mathrm{K}^{+}$, but the decrease in $\left[\mathrm{Ca}^{2+}\right]_{\mathrm{i}}$ was only slight. In the $\alpha$-toxin permeabilized rat mesenteric artery, cAMP decreased $\mathrm{Ca}^{2+}$-induced contraction (Nishimura and van Breeman, 1989). Their data indicated that cAMP decreased the $\mathrm{Ca}^{2+}$ sensitivity of the contractile elements in vascular smooth muscle. Thus, it is suggested that the inhibition of high $\mathrm{K}^{+}$-induced contraction is related to the cAMP-dependent decrease of $\mathrm{Ca}^{2+}$ sensitivity of the contractile elements.

In summary, PDE4 inhibitors are the most potent inhibitors of the U46619-induced contraction amongst the other selective PDE inhibitors used in our study in the porcine coronary artery. But in the porcine carotid artery and aorta, the potency of PDE4 inhibitors is less than other PDE inhibitors. Moreover, it is suggested that the rolipram-induced relaxation is due to a decrease in $\left[\mathrm{Ca}^{2+}\right]_{\mathrm{i}}$ levels and the $\mathrm{Ca}^{2+}$ sensitivity of the contractile elements with relation to cAMP.

\section{References}

Beavo, J.A. (1995). Cyclic nucleotide phosphodiesterase: functional implications of multiple isoforms. Physiol. Rev. 75: 725-748.

Beavo, J.A. and Reifsnyder, D.H. (1990). Primary sequence of cyclic nucleotide phosphodiesterase isozymes and the design of selective inhibitors. Trend. Pharmacol. Sci. 11: 150-155.

Bülbring, E. and Tomita, T. (1987). Catecholamine action on smooth muscle. Pharmacol. Rev. 39: 49-96.

Diamond, J. (1978). Role of cyclic nucleotides in control of smooth muscle contraction. In: Advances in Cyclic Nucleotide Research vol. 9, ed. by W.J. George and L.J. Ignarro, Raven Press, New York, pp. 327-340.

Eckly, A.E. and Lugnier, C. (1994). Role of phosphodiesterases III and IV in the modulation of vascular cyclic AMP content by the NO/cyclic GMP pathway. Br. J. Pharmacol. 113: 445-450.

Fawcett, L., Baxendale, R., Stacey, P., McGrother, C., Harrow, I., Soderling, S.H. and Beavo, J.A. (2000). Molecular cloning and characterization of distinct human phosphodiesterase gene family: PDE11A. Proc. Natl. Acad. Sci. U.S.A. 97: 3702-3707. 
Houslay, M.D., Baillie, G.S. and Maurice, D.H. (2007). cAMP-specific phosphodiesterase-4 enzymes in the cardiovascular system: a molecular toolbox for generating compartmentalized cAMP signaling. Circ. Res. 100: 950-966.

Ishida, Y. and Paul, R.J. (2005). $\mathrm{Ca}^{2+}$ clearance in smooth muscle: lesions from gene-altered mice. J. Smooth Muscle Res. 14: 235-245.

Kaneda, T., Shimizu, K., Urakawa, N. and Nakajyo, S. (2004). Effects of various selective phosphodiesterase inhibitors on carbachol-induced contraction and cyclic nucleotide contents in guinea pig taenia coli. J. Vet. Med. Sci. 66: 1047-1052.

Karsten, A.J., Derouet, H., Ziegler, M. and Eckert, R.E. (2003). Involvement of cyclic nucleotides in renal artery smooth muscle relaxation. Urol. Res. 30: 367-373.

Kikura, M. and Levy, J.H. (1995). New cardiac drugs. Int. Anesthesiol. Cli. 33: 21-37.

Komas, N., Lugnier, C. and Stoclet, J.C. (1991). Endothelium-dependent and independent relaxation of the rat aorta by cyclic nucleotide phosphodiestease inhibitors. Br. J. Pharmacol. 104: 495-503.

Li, H., Chai, Q., Gutterman, D.D. and Liu, Y. (2003). Elevated glucose impairs cAMP-mediated dilation by reducing Kv channel activity in rat small coronary smooth muscle cells. Am. J. Physiol. 285 : H1213-H1219.

Lindgren, S.H., Andersson, T.L., Vinge, E. and Andersson, K.E. (1990). Effects of isozyme-selective phosphodiesterase inhibitors on rat aorta and human platelets: smooth muscle tone, platelet aggregation and cAMP levels. Acta. Physiol. Scand. 140: 209-219.

Lindgren, S., Rascon, A., Andersson, K.E., Manganiello, V. and Degerman, E. (1991). Selective inhibition of cGMP-inhibited and cGMP-noninhibited cyclic nucleotide phosphodiesterases and relaxation of rat aorta. Biochem. Pharmacol. 42: 545-552.

Maurice, D.H., Crankshaw, D. and Haslam, R.J. (1991). Synergistic actions of nitrovasodilators and isoprenaline on rat aortic smooth muscle. Eur. J. Pharmacol. 192: 235-242.

Nishimura, J. and van Breemen, C. (1989). Direct regulation of smooth muscle contractile elements by second messengers. Biochem. Biophys. Res. Commun. 163: 929-935.

Noguera, M.A., Ivorra, M.D., Lugnier C. and D’Ocon, P. (2001). Role of cyclic nucleotide phosphodiesterase isoenzymes in contractile responses of denuded rat aorta related to various $\mathrm{Ca}^{2+}$ sources. Naunyn. Schmiedebergs Arch. Pharmacol. 363: 612-619.

Owens, G.K., Kumar, M.S. and Wamhoff, B.R. (2004). Molecular regulation of vascular smooth muscle cell differentiation in development and disease. Physiol. Rev. 84: 767-801.

Ozaki, H., Sato, K., Sato, T. and Karaki, H. (1987). Simultaneous recording of calcium signals and mechanical activity using fluorescent dye fura2 in isolated strips of vascular smooth muscle. Jpn. J. Pharmacol. 45: 429-433.

Raeymaekers, L., Eggermont, J.A., Wuytack, F. and Casteels, R. (1990). Effects of cyclic nucleotide dependent protein kinases on the endoplasmic reticulum $\mathrm{Ca}^{2+}$ pump of bovine pulmonary artery. Cell Calcium. 11: 261-268.

Schoeffter, P., Lugnier, C., Demesy-Waeldele, F. and Stoclet, J.C. (1987). Role of cyclic AMP- and cyclic GMP-phosphodiesterases in the control of cyclic nucleotide levels and smooth muscle tone in rat isolated aorta. A study with selective inhibitors. Biochem. Pharmacol. 36: 3965-3972.

Shipley, J.B., Tolman, D., Hastillo, A. and Hess, M.L. (1996). Milrinone: basic and clinical pharmacology and acute and chronic management. Am. J. Med. Sci. 311: 286-291.

Tanaka, T., Ishikawa, T., Hagiwara M., Onoda, K., Itoh, H. and Hidaka, H. (1988). Effects of cilostazol, a selective cAMP phosphodiesterase inhibitor on the contraction of vascular smooth muscle. Pharmacol. 36: 313-320.

Van der Zypp, A., Rechtman, M. and Majewski, H. (2000). The role of cyclic nucleotides and calcium in the relaxation produced by amrinone in rat aorta. Gen. Pharmacol. 34: 245-253.

Vegesna, R.V. and Diamond, J. (1986). Effects of prostaglandin E1, isoproterenol and forskolin on cyclic AMP levels and tension in rabbit aortic rings. Life Sci. 39: 303-311. 
Yamagishi, T., Yanagisawa, T., Satoh, K. and Taira, H. (1994). Relaxant mechanisums of cyclic AMPincreasing agents in porcine coronary artery. Eur. J. Pharmacol. 251: 253-262.

Yamanaka, J., Nishimura, J., Hirano, K. and Kanaide, H. (2003). An important role for the $\mathrm{Na}^{+}-\mathrm{Ca}^{2+}$ exchanger in the decrease in ctosolic $\mathrm{Ca}^{2+}$ concentration induced by isoprenaline in the procine coronary artery. J. Physiol. (Lond.) 549: 553-562.

Yoshida, T. and Owens, G.K. (2005). Molecular determinants of vascular smooth muscle cell diversity. Circ. Res. 96: 280-291.

Yuasa, K., Kotera, J., Fujishige, K., Michibata, H., Sasaki, T. and Omori, K. (2000). Isolation and characterization of two novel phosphodiesterase PDE11A variants showing unique structure and tissue-specific expression. J. Biol. Chem. 275: 31469-31479. 